\title{
What are the Tensional Goals in the Frail Elderly?
}

\author{
Rita Nascimento ${ }^{1 *}$, Marta Nazha ${ }^{1}$, Tânia Santos ${ }^{1}$ and Vasco Martins ${ }^{2}$ \\ ${ }^{1}$ Family Health Unit São Filipe, ACES Arrábida, Portugal \\ ${ }^{2}$ UCSP Praça da República, ACES Arrábida, Portugal
}

\begin{abstract}
*Corresponding author: Rita Nascimento, Family Health Unit São Filipe, ACES Arrábida, Portugal.
\end{abstract}

Received Date: December 18, 2019

Published Date: January 03, 2020

Keywords: Cardiac rehabilitation; Heart health behaviors; Health status; Adherence; Endurance

\section{Review}

In the present study we performed a literature review, aiming to understand the practical applicability of this new guidelines in the older people, and especially in frail elderly. We searched on the online database "Pubmed" the MESH terms "Hypertension" and "Frail Elderly" and we selected 32 out of 76 papers published in the last 10 years; from this 32 we selected the ones that approached the treatment targets for blood pressure. This research was complemented with the inclusion of other international guidelines and papers that were found relevant. From the papers selected to perform this review, we found guidelines, reviews and observational studies, some with conflicting results and others that are unable to define a blood pressure target in frail and institutionalized elderly. Hypertension is a well stablished cardiovascular (CV) risk factor in adults, active independent older people and even in frail elderly; nevertheless in the group of frail elderly there is evidence that they might lack a benefit in the aggressive treatment of high blood pressure. The randomized controlled trials from Beckett N, et al. [1] and Briasoulis A, et al. [2] showed that the hypertension treatment in older patients (age $\geq 65$ years) and very old patients ( $\geq 80$ years) significantly reduced CV morbidity and CV and all-cause mortality. In this studies treatment of hypertension was found to be well tolerated. The 2018 ESC/ESH guidelines recommend systolic blood pressure (SBP) target at 130-139 mmHg and diastolic blood pressure (DBP) under $80 \mathrm{mmHg}$ for elderly above 65 years. The American guidelines (2017) recommend SBP under $130 \mathrm{mmHg}$ for community dwelling older people above 65 years, but also recommend wariness in the risk-benefit relation, presence of comorbidities and limited life span. The Canadian guidelines (2018) refer to a lack of evidence to make a recommendation in blood pressure targets in institutionalized elderly [3]. The Australian guidelines (2016) recommend a target of SPB under $120 \mathrm{mmHg}$ and the British (2017) omit a recommendation referring to targets in this population.

The reviews from Correa A, et al. [4] and Naschitz J, et al. [5] refer that in frail elderly with multiple comorbidities an individualized approach should be considered and the therapeutic targets and regimes should consider risks in this population, such as possible secondary effects, potential drug interactions and that there may be a need for deintensification of antihypertensive treatment $[6,7]$. A review from Ferri C [8] contemplates more aggressive targets in the eldery, for the author defend that hypertension is major CV risk factor and not its treatment. Nevertheless, the inclusion of frailty evaluation in clinical practice is of major importance to make decisions. The Systolic Blood Pressure Intervention Trial (SPRINT) (2015), showed that a SBP target under $120 \mathrm{mmHg}$ for most elderly was reasonable. This trial included a significant amount of elderly participants above 75 years old and demonstrated that a more aggressive treatment significantly reduced major CV events, heart failure and all-cause mortality, all above $30 \%$, with statistical significance, in comparison with standard treatment. This trial also suggests that this benefits may extend to frail elderly. Based on this trial, with outstanding results, the ESC/ESH taskforce made the new recommendations in the 2018 guidelines to people above 65 years. A cohort study by Corrao G, et al. (2017) [9], refers that adhesion to anti-hypertension treatment was associated with a reduction in the risk of CV events e CV mortality, even in ages above 85 years old. 


\section{Conclusion}

Based on this review, we consider that there is recent evidence to support the definition of more strict targets in the elderly regardless of chronological age. However, we consider that frailty should be assessed in clinical practice with an evaluation tool and taken into consideration for an individualized approach in the treatment of hypertension.

\section{Acknowledgements}

None.

\section{Conflict of Interest}

No conflict of interest.

\section{References}

1. Beckett NS, Peters R, Fletcher AE, Staessen JA, Liu L, et al. (2008) Treatment of Hypertension in Patients 80 Years of Age or Older. N Engl J Med 358: 1887-1898.

2. Briasoulis A, Agarwal V, Tousoulis D, Stefanadis C (2014) Effects of antihypertensive treatment in patients over 65 years of age: a metaanalysis of randomised controlled studies. Heart 100(4): 317-323.

3. Williams B, Mancia G, Spiering W, Agabiti Rosei E, Azizi M, et al. (2018) 2018 ESC/ESH Guidelines for the management of arterial hypertension:
The Task Force for the management of arterial hypertension of the European Society of Cardiology (ESC) and the European Society of Hypertension (ESH). European Heart Journal 39(33): 3021-3104.

4. Ashish Correa, Yogita Rochlani, Mohammed Hassan Khan, Wilbert S Aronow (2018) Pharmacological Management of Hypertension in the Elderly and Frail Populations. Expert Review of Clinical Pharmacology 11(8): 805-817.

5. Naschitz J (2018) Blood pressure management in older people: balancing the risks. Postgrad Med J 94(1112): 348-353.

6. Wright JT Jr, Williamson JD, Whelton PK, Snyder JK, Sink KM, et al. (2015) A Randomized Trial of Intensive versus Standard Blood-Pressure Control. N Engl J Med 373(22): 2103-2116.

7. Warwick J, Falaschetti E, Rockwood K, Mitnitski A, Thijs L, et al. (2015) No evidence that frailty modifies the positive impact of antihypertensive treatment in very elderly people: an investigation of the impact of frailty upon treatment effect in the HYpertension in the Very Elderly Trial (HYVET) study, a double-blind, placebo-controlled study of antihypertensives in people with hypertension aged 80 and over. BMC Medicine 13: 78.

8. Ferri C, Ferri L, Desideri G (2017) Management of Hypertension in the Elderly and Frail Elderly. High Blood Press Cardiovasc Prev 24(1): 1-11.

9. Corrao G, Rea F, Monzio Compagnoni M, Merlino L, Mancia G, et al. (2017) Protective effects of antihypertensive treatment in patients aged 85 years or older. J Hypertens 35(7): 1432-1441. 